\title{
La situación de los presos en las cárceles del Santo Oficio de Granada durante el siglo XVII
}

\author{
maría Helena Sanchez Ortega *
}

A pesar de la leyenda tejida en torno a la situación de los presos en las cárceles inquisitoriales -terrible y misteriosa, de acuerdo con la literatura - la opinión tradicional de los autores que se han ocupado de la cuestión, como Llorente, Lea, Schaeffer, Kamen y más modernamente J. I. Tellechea, suele ser unánime. La situación de los presos en las cárceles inquisitoriales era "mejor" que la de aquéllos que cumplian sentencia en las dependencias de los tribunales civiles. Esta interesante afirmación merece, sin embargo, un detenido análisis que voy a intentar llevar a cabo en las páginas que siguen.

En primer lugar, conviene señalar lo aventurado que resulta establecer una comparación entre las cárceles dependientes de los tribunales civiles y las inquisitoriales, en el presente estado de las investigaciones respecto a las dos instituciones. Las noticias que tenemos en ambos casos son sumamente fragmentarias y me parece bastante arriesgado dar una opinión global, especialmente cuando se trata de un periodo tan amplio - siglos XVI, XVII y XVII- durante el cual sabemos que se siguieron criterios no siempre coincidentes. Sería necesario, por tanto, conocer más a fondo la situación de los presos en las prisiones reales antes de hacer una afirmación tan tajante.

\footnotetext{
* Universidad Nacional de Educación a Distancia UNED.
} 
A pesar de ésto, los datos conocidos ${ }^{1}$ hasta ahora parecen sugerir que, efectivamente, la situación de las personas encarceladas por el Santo Oficio no era tan terrible como se podría pensar en principio.

Evidentemente, estamos ante un problema importante al que deberia dedicarse alguna monografía que sirviera para arrojar una luz definitiva acerca de esta incidencia del antipático tribunal sobre la población española. Las dificultades que impiden abordar este tema son, sin embargo, tan grandes que a ellas debe atribuirse, probablemente, que no se haya llevado a cabo todavía.

La normativa dictada es relativamente conocida. Tellechea alude a las "Instrucciones" de Sevilla (1484), Valladolid (1488), Avila (1498) y las normas dictadas por Adriano de Utrech en 1517, Carlos V en 1518 y la Suprema en 1570. Sin embargo, las instrucciones no tenian demasiado que ver con la realidad. A lo largo de los siglos XVI y XVII se pueden observar con claridad los esfuerzos realizados por las distintas inquisiciones provinciales para conseguir cárceles estables o para situar a sus condenados. Según Tellechea, los tribunales de Valencia, Logroño, y Toledo no disponian de prisiones estables ${ }^{2}$.

Según vemos, las dificultades de los inquisidores para mantener encerrados a sus reos eran grandes, pero, por lo general, la impresión que produce la lectura de los procesos inquisitoriales, es que la prisión y aislamiento consiguiente, antes y durante el proceso, se mantenía rigurosamente. Algunas inquisiciones estaban instaladas en castillos fortificados, como la de Zaragoza en la Aljafería y la de Sevilla en el de Triana, los antiguos calabozos de estas fortalezas se utilizaban para retener en ellos a los reos que se iban a juzgar, y Kamen estima que el buen estado de estos calabozos explica la buena reputación de las "cárceles secretas" inquisitoriales ${ }^{3}$.

La prisión que podriamos denominar "preventiva", por tanto, no parece ofrecer lugar a dudas. Mientras el acusado estaba en espera de

\footnotetext{
1 La situación de los presos y de los tribunales civiles cuenta ya con algunos trabajos, como los contenidos en el número especial de Historia 16, "Las cárceles en España" Historia 16, 16 oct. 1978, extra VII. El estudio de Ruth PIKE: Penal servitude in early modern Spain. Wisconsin University 1983.

$2 \mathrm{~J}$. Ignacio TeLLECHEA: “Las cárceles inquisitoriales». ob. cit., pág. 55-67. Las cárceles en España, en Historia 16, 1978.

${ }^{3}$ Henry Kamen: La Inquisición española, Madrid, Alianza Editorial.
} 
juicio - etapa que podía durar varios años - y en el curso de su proceso, el encarcelamiento se mantenía con rigor, y no se observan casos de presos que pudieran circular con libertad una vez que los inquisidores habian Ilegado hasta ellos.

Una vez que se había dictado la sentencia, la situación variaba bastante, según veremos a continuación.

Según las Instrucciones de 1488 , los inquisidores podian permitir a los condenados que cumplieran la pena de prisión perpetua en sus propias casas, en vista de las dificultades con las que se tropezaba para disponer de cárceles suficientes para todos los condenados. Las dificultades de este orden obligaron a los inquisidores a conmutar a muchos reos la prisión perpetua por el confinamiento a lo largo del siglo XVI, en conventos muchas veces 0 en sus propias casas cuando se trataba de mujeres ${ }^{4}$.

Como es lógico, el Santo Oficio era consciente de la limitación que representaba para sus atribuciones la ausencia de prisiones donde obligar a los condenados a cumplir las penas que les habían correspondido, $y$ en las Instrucciones de 1561 se autoriza a los tribunales a comprar casas particulares para que los condenados puedan respetar en ellas la cárcel que se les ha asignado. En 1570 , la Suprema ${ }^{5}$ vuelve a autorizar a los tribunales sin cárceles para que habiliten casas particulares, y a partir de 1600 parece que el Santo Oficio empezó a hacer esfuerzos para construir edificios destinados a ser utilizados como cárceles. Lea ${ }^{6}$ señala que en 1600 aparece una alusión en el tribunal de Toledo a la "cárcel de penitencia" y en 1610 el de Valencia estaba ocupado en la construcción de un edificio de tres plantas para estos fines. De acuerdo con el informe del fiscal Crespos, del tribunal de Granada, que analizaremos a continuación, a mediados del siglo XVII casi todos los tribunales disponian ya de cárceles apropiadas. A pesar de esto, los condenados estaban muy lejos de observar un confinamiento riguroso, según se verá.

\footnotetext{
4 Algunas beatas importantes como la de Piedrahita, o la misma María de Cazalla fueron condenadas a permanecer confinadas en sus casas. Algunas monjas "revelanderas", como Sor María de Carrión, pasaron sus condenas en sus propios conventos. Esto no quiere decir, sin embargo, que los condenados a confinamiento fueran siempre mujeres.

5 J. I. TELLECHEA: artí. cit.

6 H. Ch. LEA: A History of the spanish Inquisition, Reimpr. en Nueva York. Ams Press, 1966, 4 tomos, (tomo IV).
} 
Otra dificultad con la que tropezó el Santo Oficio para obligar a sus condenados a cumplir la pena de prisión fue el mantenimiento de una población reclusa que en algunos tribunales y momentos llegó a alcanzar un número importante de hombres y mujeres. Como es sabido, el acusado quedaba privado de sus bienes desde el momento mismo en que se iniciaba su proceso a causa de la confiscación que se practicaba habitualmente, tanto si se trataba de un pobre mendigo, como de un adinerado judio, y a partir de aquí, el prisionero quedaba en una situación, respecto a su propio mantenimiento, que todavía no conocemos con exactitud. Según H. Ch. Lea ${ }^{7}$ los presos ricos eran alimentados mediante el secuestro de sus bienes que se secuestraban, en un principio, con este fin, y los pobres, gracias a las limosnas y ayudas de los amigos y parientes. En la práctica, la lectura de los procesos produce la sensación de que hubo una gran variedad de situaciones, que iban desde la posibilidad de que un preso rico siguiera teniendo varias personas a su servicio, como sería el caso del obispo Carranza ${ }^{8}$, o la de los presos más pobres, condenados a recibir las raciones repartidas por el "despensero" de la cácel. En otras palabras, no existía una regla fija, y la situación de los encarcelados se complicaba cuando se trataba de dejar transcurrir la prisión consignada por el tribunal. Como es lógico, los que salian mejor parados eran aquéllos a quienes se conmutaba la pena por la de confinamiento en sus propias casas, donde podian estar seguros de recibir la ayuda de las personas cercanas.

Mucho más difícil, sin embargo, parece la de aquellos que debieron permanecer en los lugares reservados como cárceles por la propia Inquisición. En 1512, los inquisidores se decidieron a autorizar a los que habían sido condenados a prisión perpetua para que salieran por las calles a pedir limosna, siempre que llevaran con ellos sus sambenitos, lo que parece indicar que padecían una miseria grande. En 1654 la situación se repite en el tribunal de Granada, y gracias a los memoriales que dirigieron los propios presos y la protesta de uno de los miembros del tribunal ante este estado de cosas contamos con datos suficientes para describir la situación con cierto detalle.

De acuerdo con uno de los memoriales, impreso y dirigido por el doctor D. Francisco José Crespos de Escobar, fiscal de la Inquisición de Granada y miembro del Consejo real, convenía impedir que los reconcilia-

7 LEA: op. cit., tomo IV.

${ }^{8}$ LEA: Op. cit., tomo IV. 
dos anduvieran por las calles vendiendo mercancias, y en lugar de esto volvieran a las "tiendas particulares", tal y como estaba dispuesto en un auto de gobierno de la Inquisición de esta ciudad. El fiscal apuntaba también que en algunos casos seria mejor que se “redujeran» a «mayor clausura y observancia formal de cárcel en esta y las demás inquisiciones", tal y como estaba dispuesto en las instrucciones del Santo Oficio.

Las razones en las que se apoya el doctor Crespos de Escobar habian sido expuestas con anterioridad por el propio corregidor de Granada quien se había dirigido a los inquisidores para exponerles la opinión del cabildo a este respecto. De acuerdo con el razonamiento del corregidor, de que se hace eco el fiscal del tribunal en su memorial, en primer lugar convenía evitar que estos reconciliados anduvieran por las calles, porque "con el pretexto de vender sus mercadurias, buscavan y colicitaban deshonestidades", aspecto que resulta bastante sorprendente y poco creible a la vista de las razones a las que se alude a continuación. Las razones de orden económico que se exponen con todo detalle en segundo y tercer lugar resultan bastante más convincentes: «...pues estos hombres, como exemptos de la real jurisdicción, tienen mano y maña para defraudar los derechos de la alcavala y otros impuestos, correspondientes a la venta de sus mercadurias, cargando esto sobre los demás mercaderes y vezinos". El corregidor pensaba que de esta forma - lo que indica en tercer lugar - se originaba un grave perjuicio a los habitantes de la ciudad,

«...pues con andar estos hombres por las calles, y casas vendiendo, se les quita la mayor parte del comercio en sus tiendas, nadie va a ellas, podiendo en su casa comprar y escoger, y con mayor comodidad de precios que estos hombres hazen: ellos se entienden, y no se pierden en el trato; antes vemos que saliendo casi desnudos de las cárceles secretas y, los más, confiscados sus bienes, se visten, se alajan, y enriquezen con grandisima brevedad" ${ }^{9}$.

Como vemos, se trataba de un caso de competencia comercial en el que, al parecer, la movilidad de los presos que acudian a vender por las casas dejaba en una situación relativamente difícil a los comerciantes estables y con tienda propia. Ciertamente, la situación descrita por el corregidor por lo que se refiere a los condenados de la Inquisición, mo-

${ }^{9}$ Archivo Histórico Nacional. Inquisición. Leg. 2635 n. 14. 
viéndose con tanta libertad que incluso tenían tiempo para "deshonestidades" no deja de ser llamativa, aunque, según veremos a continuación, el corregidor había pintado las cosas en tonos excesivamente halagüeños impulsado, sin duda, por su deseo de proteger los intereses de los propietarios de las tiendas, etc.

De acuerdo con la petición del corregidor, los inquisidores decidieron mediante un auto que los penitenciados contaran con un plazo de veinte días para liquidar sus mercancías, que podian pregonar y vender por las calles o en los zaguanes de las casas sin llegar a entrar en ellas, pasados los cuales se les prohibía seguir con sus ventas.

Como es lógico, los presos protestaron de esta determinación, alegando que se trataba de una costumbre practicada en todas las Inquisiciones de España y ante la imposibilidad de ganar dinero para sustentarse ellos mismos y sus hijos, y así se inició la discusión entre estos desgraciados y el fiscal del tribunal que nos proporciona las noticias acerca de este estado de cosas característico de las cárceles inquisitoriales en toda la península, según alegan ambas partes en litigio.

En el larguísimo memorial dirigido por el fiscal a la Suprema se aducen todas las razones que hacen aconsejable el estricto cumplimiento de la pena de cárcel, de acuerdo con un criterio consecuente con la existencia del tribunal y su facultad de privar de libertad a los herejes, bígamos, sodomitas, y demás "delitos" en los que entendian sus colegas.

Evidentemente, las razones expuestas por el doctor Crespos de Escobar, a pesar de su evidente lógica, no resultan convincentes al hombre de hoy que no puede dejar de recordar el carácter repudiable del tribunal inquisitorial, tan eficaz y exacto desde el punto de vista jurídico por otra parte.

Las razones expuestas por el fiscal se refieren, como es lógico, al ordenamiento jurídico de la Inquisición, y a la necesidad general de hacer cumplir las penas que habían sido dictadas por los distintos inquisidores. El doctor Crespos alude a las instrucciones de Valladolid de 1488, en cuyo capítulo 10 se permitía que se instalara a los presos en casas particulares de forma provisional - según analicé al principio- mientras se conseguía habilitar cárceles para todos los presos reunidos. Crespos se apoya también en el capitulo 14 de estas mismas instrucciones, en que se describe con más detalle las características que deben tener estos lugares: 
«...que en cada partida donde la Inquisición se haze, se haga en los lugares dispuestos un circuito quadrado con sus casillas, donde cada uno de los encarcelados estén y se hagan una Capilla pequeña, donde oygan Misa algunos dias"

Según el fiscal, estos lugares ya están construidos, y en Granada las hay «de bastante capacidad». Es decir, no existe ningún pretexto por lo que se refiere a la existencia de locales apropiados, para que no se cumplan las siguientes instrucciones inquisitoriales en este punto, que serian, de acuerdo con el fiscal Crespos, las de Madrid de 1571, en las que se vuelve a señalar la necesidad de mantener encerrados a los condenados. El capitulo citado por el fiscal es muy explícito y conviene repetirlo:

“...los entregarán el Alcayde de la cárcel perpétua (subrayado en el original) mándandole tenga cuydado de su guarda, y de que cumplan las penitencias, y que les avise de los descuydos, si algunos huviere en ellos. $Y$ también procure, que sean proveydos, $y$ ayudados en sus necesidades con hazerles tener algunas cosas de los oficios que supieren, con que se ayuden a sustentar y pasar su miseria».

La actitud del Santo Oficio, como vemos, era muy clara. Los condenados debian pagar su pena en el interior de las cárceles, y ayudarse con su propio trabajo para su sustento. El doctor Crespos cree conveniente a continuación dar fuerza a sus argumentos mencionando la tradición conciliar. Los concilios a cuyo criterio se remite son el de Tolosa (capítulo 10), el Concilio Narbonense (capítulo 9), y la instrucción $14 \mathrm{del}$ Biterrense ${ }^{10}$. La tradición eclesiástica, según estos concilios, era partida-

10 «No deve dudarse de la fuerça de estas instrucciones, aun quando no fueran, como son, en conformidad con tantos Concilios y Decretos antiguos, Concil. Tolosan, cap. 10 ibíd: Haeretici autem, qui timore mortis, vel alta quacumque causa, dummódo non sponte redierint ad Catholicam unitatem ad agendam paenitentiam per Episcopum loci in muro, cum tali includantur cautela. (sic) Lo mesmo era antiguamente, Immurar, que aora, encaercaler en cárcel perpetua. Pegn. in 3 part. direct. lib. 3 Schol. 65.

El Concilio Narbonense cap. 9 ibid: Quamuis tales proculdubio sint, secundum statuta Domini Papae IN PERPETUO CARCERE detrudendi. Y más claramente, y conforme a la dicha instrucción 14, el Concilio Biterrense (al qual algunas vezes cita Petr. Crespe in Summa Catholica) cap. 23 ibid: Curetis tamen, ut talibus immurandis, fian, iuxta Sedis Appostilicae ordinationiem, SEPARATAE, ET OCCULTAE CAMARULAE, sicut fieri poterit in singulis Civitatibus Diacesum corruptarum, ut alterutrum, vel se, vel alios corrumpere nequeant, (t) eos enormis rigor carcerum non extinguat. $Y$ para que no se dude, que habla de esta cárcel perpetua, prosigue en el capt. 24. HAEC AUTEM PERPETUI CARCERISP POENA, SEV POENITENTIA, nulli ab initio de praefactis cuipabilibus remittatur. 
ria de la pena de cárcel para los culpables de herejia, y en el mismo sentido se habían pronunciado también otras autoridades que menciona el memorialista, como el emperador Federico y Gregorio IX. En consecuencia con estos argumentos, Crespos insiste en que las instrucciones inquisitoriales respecto a la pena de cárcel deben interpretarse en el sentido más estricto:

«De las referidas instrucciones, Concilios y doctrina, se reconoce claramente la intención de tener a los penitenciados en formal clausura; esso quiere dezir la palabra Cárcel, y encarcelados, tantas vezes repetida en las instrucciones".

Los argumentos de nuestro memorialista pueden parecer un tanto ingenuos, e incluso tautológicos, desde una perspectiva actual, pero no lo son tanto si atendemos - desde su punto de vista - a la situación que explica con claridad a continuación: "Y deviendo verificarse la mayor parte de esta pena - alude a la severidad de la clausura de la que se habla en los concilios- en los penitenciados reclusos, nada casi se verifica mas que el nombre; salen de la carcel a todas las horas del día, sin limitación de tiempo, sin compañia de persona, sin gravamen de ocupación, mas la que ellos voluntariamente eligen; esto es literalmente la libertad... no padecen estrechura ni incomodidad de vivienda, porque aunque la carcel fuera estrecha y desacomodada (la de este Santo Oficio es bastantemente capaz) no están en ella en todo el dia, ni aún parte de la noche... Su carcel es toda Granada, los arrabales, los campos, las huertas, y todas las salidas de recreación, las casas, las de algunos vezinos a donde juegan y se entretienen siguiendose a caso algunos de los inconvenientes o escándalos que pondera la Ciudad, de manera que la carcel de la penitencia pareze (permitáseme dezirlo assi) que no les sirve más que para escusarles de pagar alquiler de casa a título de reclusos; esta carcel mas tiene de conveniencia, que de incomodidad y nada de semejança de muerte, ni de sepulcro de vivos": Crespos concluye este aspecto de su argumentación lamentándose abiertamente: «De que sirve, señor, llamarse carcel, y carcel de penitencia, o perpetua?"

A continuación, Crespos pasa a exponer con todo detalle los perjuicios que se derivan de este estado de cosas, fundamentalmente desde el punto de vista del hombre de leyes, aunque sin desdeñar las razones expuestas también por el corregidor. En primer lugar, sería preciso tener 
en cuenta, según nuestro memorialista, el incumplimiento del castigo, hecho tan grave que incluso llega a decir, "y tengo (aunque parezca paradoxa) por menos prejudicial dexar alguna vez totalmente sin castigo un delito, que hazer costumbre a mitigar la pena del...". Para Crespos, la tolerancia respecto a las penas legales resta fuerza a las leyes y hace que pierdan sentido ${ }^{11}$.

En segundo lugar, el sentido de las instrucciones inquisitoriales pierde también valor, y resulta imposible que los alcaides cumplan con la misión que se les encomienda en ellas de vigilar a los presos ${ }^{12}$.

Como consecuencia de esta falta de vigilancia, los presos no se arrepienten de sus culpas ni viven en las cárceles con la "honestidad y recogimiento" debidos, según lo testimonia una carta acordada del Inquisidor General a la que alude Crespos de 15 de marzo de 1607 dirigida al propio tribunal de Granada ${ }^{13}$.

En tercer lugar, Crespos señala la conveniencia -según se indica en los Cánones y Concilios, aunque no lo indiquen expresamente las instrucciones del Santo Oficio- de impedir la comunicación frecuente entre los condenados y el resto de los fieles, aspecto que considera

11 "Y tengo (aunque parezca paradoxa) por menos prejudicial dexar alguna vez totalmente sin castigo un delito que hazer costumbre mitigar la pena, aquello puede ser olvido, o ignorancia, o sea desprecio de la ley, o transgresión, en fin, es culpa clara, que traspassa la ley, pero no la deshaze, conocese la culpa como culpa, y quedase la ley en su fuerça; pero el mitigar las penas legales de costumbre, es ir cercenando las leyes, es irlas deshaziendo, parece, que las guardan y se pierden; a pocas remisiones en parte, se introduce relaxación en el todo. Al Juez le parece piedad la remission (ha mucho que este vicio pretende vestirse de aquesta virtud)...".

12 «De aqui se infiere el perjuycio que se sigue a la causa publica en defraudar a esta pena de carcel en las permissiones introduzidas tanta parte de lo substancial de la pena, es publico interés, no solo que los delitos no queden sin castigo, sino que queden tambièn enteramente castigados...".

${ }^{13}$ "Y de que estos reconciliados no han vivido en las cárceles con la honestidad y recogimiento que se devia, es testigo mayor de toda excepción una carta acordada de V.A. escrita en 15 de Março, año 1607 a este Tribunal, mandando (por aver entendido que los reconciliados no vivian con el recogimiento y honestidad necessari) que la carcel de la penitencia se dispusise de manera, que se evitasse la comunicación de hombres y mugeres, y que se les hiziesse Capilla para oyr Missa, y pláticas espirituales en que se conoce que si para esto, quiso V.A. escusar que saliesen, tan grande y tan antiguo ha sido el cuydado de V.A. en esta materia como lo es en todas, creciendo cada dia con incasables desvelos y progressos casi milagrosos en servicio de Dios...". 
realmente importante, y cita al respecto la autoridad de varios concilios como el de Tolosa, y autores eclesiásticos ${ }^{14}$.

El memorial dedica bastante espacio a ponderar los peligros que se derivan del trato con los condenados, especialmente porque es preciso, según Crespos, proteger a los fieles virtuosos de unos herejes cuyo arrepentimiento es dudoso:

"De esta provable duda de verdadera conversión deve nacer el cautelar el peligro de las comunicaciones, acompañarle de buenos, es buscar exemplo para la virtud, y defensa contra el vicio; llegarse a los malos, es entrarse por el riesgo de perderse».

Finalmente, Crespos cree conveniente apoyar las razones expuestas por el Corregidor de Granada, acerca de los perjuicios ocasionados a los mercaderes estables e incumplimiento de la ley.

Para completar su exposición, el fiscal Crespos se ocupa de refutar los argumentos de los presos, sobre los que volveré a continuación, utilizando el propio memorial de los interesados. Según Crespos, sus quejas acerca de la miseria que padecen, la de sus mujeres e hijos y la costumbre establecida en otras inquisiciones que permite a los presos vender en las calles en otras inquisiciones no deben ser tenidas en cuenta, puesto que todo esto son inconvenientes que deben padecer como parte de sus condenas, y también su familia debe compartir el castigo:

«ÿo confiesso, que padecerán pobreça, la qual en el siglo presente, es pena grave... $Y$ que en esta tan penosa circunstancia, serán mancomunados muger y hijos, y aunque no hayan sido (que no será poco) complices en la culpa, pero todo esto aun es pequeño castigo en delitos

14 «El tercero motivo, aunque no le expressan las instrucciones, se deve suponer como muy principal y necessario, advertido de los sacros Canones, y antiguos Concilios, que es el apartar de la frequente comunicación destos penitenciados a los demas Fieles; y es de tanta importancia este fin, que dudaron algunos Canonistas antiguos, quos citat Fatin de haeretici quest 193. 5. num. 101. Si por el principalmente o por el primero que diximos se introduce esta perpetua carcel; entre otros Joann. de Annan in cap. escomunicamus, el 2 cap. fin de haret in summario num. 3 ponit: An iste penitene ad perpetuos carceres amnetur ad penam, an vero NEALIOS INFICIAT». 
desta calidad, pues para hazerlos mas horribles no se castiga solamente a las personas de los Reos, sino a sus familias y descendencias."

Para nuestro severo fiscal, los condenados deben padecer la pobreza de que se quejan como mejor medio para expiar sus culpas:

«Para pasar su necesidad, y miseria, en que deven estar, como lo dan a entender las instrucciones referidas supr (...) ellas mesmas apuntan el remedio, que es valerse de oficio, con que se puedan sustentar. Replican a esto, que no los saben, ni pueden aprenderlos, porque les falta maestros, capacidad y disposición respecto de sus años. Esto dizen ellos, lo que sienten todos es, que no les falta capacidad, antes les sobra industria y disposición para aprender todo aquello a que se aplicaren. Yo añado que también tienen assi pagado el mejor maestro del mundo para aprender sin costa todos los oficios y artes. El maestro es la mesma pobreza, que huyen.»

Como vemos, la actitud del fiscal del Santo Oficio era realmente dura, lo que no dejaba de resultar lógico si tenemos en cuenta su condición de funcionario inquisitorial, pero esta severidad quedaba paliada, de alguna manera, por el argumento que introduce como colofón de su larguísimo alegato, según el cual la pena de cárcel perpetua no excedía, en la realidad de los tres años de prisión:

"La pena desta carcel, aunque suena perpetuidad, lo ordinario es de tres años; y siendo de tiempo tan corto, es menester menos prevención de medios; passen como pudieren y padezcan; sirvan a Dios, y fien en su misericordia con verdadera fe y confiança, que a buen seguro que no les falte sustento, ni consuelo...".

Hasta aquí hemos visto el punto de vista de un miembro de los tribunales inquisitoriales. Según he tratado de poner de relieve en el resumen anterior, las razones de los funcionarios inquisitoriales se apoyaban al mismo tiempo en la tradición de la Iglesia, el derecho canónico, y las instrucciones de carácter jurídico del propio tribunal del Santo Oficio. La norma a seguir era, por tanto, muy clara, pero la fuerza de los hechos imponía a estos celosos vigilantes de la salud de las almas sus propias reglas, y una vez más, la realidad difería bastante de los fundamentos 
teóricos. Los condenados por los tribunales inquisitoriales, según hemos visto aducir al fiscal Crespos, salian y entraban de la prisión cuando les parecía oportuno, vendian mercancias por las calles, y sólo regresaban para cumplir la penitencia cuando les venía en gana. Una situación ciertamente chocante, especialmente si tenemos en cuenta la terrible fama del Santo Oficio. Veamos a continuación, sin embargo, cuál era el estado de cosas desde el punto de vista de los propios interesados.

Según el escrito que dirigieron estos penitenciados a la Suprema, casi todos ellos habían sido condenados en el auto que se habia celebrado en Granada el año anterior, el 31 de noviembre de 1653, y en el año que habían pasado en la cárcel de la ciudad no habían dejado de experimentar los "saludables" sufrimientos que el fiscal Crespos deseaba para el perfeccionamiento de sus almas ${ }^{15}$. Al igual que en el caso de los argumentos del fiscal, es mejor recurrir ahora a los términos utilizados por las víctimas de este caso:

«... y por causa de estar destituydos de nuestras haciendas, y sin remedio ninguno para el sustento de nuestras familias ser grandes a la mendiguez, tomando huna capacha por las calles. $Y$ aunque a los principios fuimos favorecidos con algunas limosnas, despues cessaron y no so esso pero obligava nuestra miseria a que algunas personas nos maltratasen de palabra y quisieren matar. Con que nos fué forçosso dexar las capachas y acudir a las puertas de los conbentos baliendonos de las limosnas que en ellos dan, donde tamvien se orixinaron grandissimas dissinsiones con los muchos pobres que ellos acuden, y para obiarlas fué necessario el dexar la asistencia" ${ }^{16}$.

La situación no era fácil para los penitenciados del Santo Oficio. Su presencia por las calles despertaba la animosidad de algunas personas, y cuando intentaban acogerse a la limosna de los conventos tropezaban con la suspicacia de los numerosos pobres que vivian a costa de los frailes y monjas que repartian la "sopa boba". Evidentemente, recurrir a

${ }^{15}$ Crespos es, como de costumbre, muy tajante a este respecto, y recomienda el sufrimiento como buena medicina para las almas de los condenados. incluso asegura que sus cárceles deben ser similares a sepulcros: «... no debe tener libertad, quien desestimando la de Christiano se sugetó infielmente a la servidumbre del demonio, pierde el dominio de si, como de todas las cosas... No debe gozar de comodidad de vivienda quien tan poco antes fue serpiente, o escorpion, basta para un sepulchro otro sepulchro...".

${ }^{16}$ AHN. Inquisición, leg. 2636 n. 43. 
la caridad pública, tanto de los conventos como de los particulares, no era la mejor solución en la España agobiada por la crisis económica de mediados del siglo XVII. Ni para los penitenciados del Santo Oficio, ni para las ciudades que se veían obligados a sustentarlos.

Afortunadamente para todos, la solución había llegado de la mano de un miembro del propio tribunal de la Inquisición, quien ejercía también como «mercader en gruesso" y "llevado de la piedad" - según la expresión de los firmantes, aunque es probable que también tuviera en cuenta otras consideraciones - les entregó algunas cantidades de lienzo para que la vendieran por las calles. El mercader-funcionario les fijaba también los precios en que debian vender los paños, y ocupándose semanalmente de recoger el dinero de las ventas. El caso, por tanto, era más complejo de lo que parecía a primera vista puesto que el mercader pertenecía al gremio correspondiente y pagaba las alcabalas que se suponía eludían los improvisados vendedores. Los presos solicitan en su escrito que se revoque el auto según el cual se les prohibia vender por las calles, insistiendo en su mucha miseria, y la ausencia de razones de orden económico aducidas por el corregidor.

«... hablando con el respeto devido (el auto) es de revocar, lo primero, por las causas y raçones propuestas; lo otro, porque si se nos impidiese este exercicio quedamos absolutamente pribados de todo remedio y no hallandonos ninguno de nosotros con oficios a que podernos arrimar, que aunque algunos saven leer y escrebir, y queriendonos baler de ello no es bastante a podernos sustentar, ni tampoco ay quien nos de para el uso de ello. Lo otro porque el dicho mercader que nos fia paga dichas alcavalas y demas derechos cargándonoslas en los precios. Con que este verificado el odio de dicho gremio".

El auto dictado por el tribunal inquisitorial a causa de la petición del Corregidor había venido a complicar la situación de los condenados, no sólo porque le impedía ganarse la vida según lo habian hecho durante los últimos meses, sino porque el plazo que se les había concedido para liquidar sus existencias no había sido suficiente, y los presos dirigieron también otro escrito suplicando que se les ampliaran los veinte días a sesenta durante los cuales pudieran andar todavía libremente por las calles con sus mercancias.

Según vemos, la necesidad de los presos había dado la mano en esta ocasión a los intereses de un miembro del Santo Oficio, permitiendo 
la chocante situación de un grupo de condenados a "cárcel perpetua" que salen y entran de su prisión para vender lienzos por las calles. Según otra carta que aparece en el mismo legajo ${ }^{17}$ en total serían unas 80 personas las afectadas por el auto del tribunal de Granada, si se tenían en cuenta a los familiares de los detenidos además de los propios interesados, muchos de los cuales habian sido condenados por judaizantes, al parecer, puesto que se habla en varias ocasiones de la obligación que tienen de llevar con ellos sus sambenitos.

El pleito entre los presos-mercaderes y el corregidor de Granada hizo correr bastante tinta, pero, desgraciadamente, no tenemos constancia de cuál fue el resultado final de este conflicto. Probablemente, los presos continuaron todavía con su negocio, puesto que no había otra solución para su perentoria necesidad. ${ }^{18}$

Según espero haber puesto de relieve, los memoriales del fiscal Crespos y de los presos del tribunal de Granada sirven para comprender mejor las circunstancias de los condenados a penas de cárcel por el tribunal de la Inquisición, muy lejos del aspecto más o menos pintoresco que la primera lectura del escrito de Crespos pudiera producir en un lector actual. Aunque, según se pone de relieve en el memorial impreso por Crespos, la visión que tenían los inquisidores de la pena de cárcel estaba muy próxima de la de los jueces de la época industrial, las circunstancias socio-económicas del Antiguo Régimen no permitian llevar a la práctica sus principios con todo el rigor que ellos hubieran deseado, y se veían obligados a transigir con comportamientos muy diferentes que, como es obvio, no sólo beneficiaban a los desgraciados condenados de un tribunal empeñado en juzgar las conciencias, sino a un país en el que la mendicidad y los grupos ociosos siguieron siendo un problema durante todo el siglo XVIII.

A pesar de la libertad de que pudieran gozar los penitenciados, los hombres y mujeres que caían en las manos de los inquisidores no dejaban de intentar librarse de ellos a cualquier precio, y los conatos de fuga eran tan frecuentes como en cualquier tribunal laico, lo que parece indi-

17 Ibidem, leg. 2636, n. ${ }^{\circ} 43$.

18 Efectivamente, en la sección "Cartas al Consejo" aparece todavia una noticia a propósito de los presos de las cárceles granadinas el 25 de octubre de 1721 , "...de los reconciliados y presos en las cárceles de la penitencia del Tribunal de Granada que representan la necesidad que tienen se les socorra con limosna se les conceda libertad". A.H.N., Inq. leg. 2.615. 
car que los condenados no se sentían tan cómodos en las cárceles inquisitoriales como suponía Crespos. Unos cuantos años antes de los hechos que acabo de referir tuvo lugar en el mismo tribunal de Granada un intento de fuga que terminó de forma bien trágica para sus protagonistas. Unos presos llamados Pedro Rodríguez, pastor natural de Vaña, del obispado de Astorga, y Juan López de la Oliva, natural de Oliva, en el obispado de Plasencia, intentaron escapar de las cárceles secretas prendiendo fuego a la puerta de la cárcel, "que era nueva, y muy fuerte, y por ser la carcel de bobeda no pudo salir el humo y los ahogó y se hallaron muertos $y$ ahogados sobre sus camas, $y$ el uno con sus grillos muy machacados, vestido, y el otro en carnes..." ${ }^{19}$. Ambos estaban acusados de bigamia.

19 Ibidem, 2400 (1) (27 de septiembre de 1606). 